\title{
Rheological properties of cement slurries modified by silica nanostructures applied in drilling industry
}

\author{
Anna Pikłowska ${ }^{1, *}$ \\ ${ }^{1}$ AGH University of Science and Technology, 30 A. Mickiewicz Av., 30-059 Kraków, Poland
}

\begin{abstract}
The most important purpose of cementing boreholes is to counteract the inflow of deepseated waters into productive levels of oil and gas-bearing rocks. The increasing requirements regarding the properties of cement grout and cement stone enforces the search for unconventional solutions and materials that will provide a resolved improvement in their properties and resistance to temperature and chemical factors in difficult geological and reservoir conditions. Therefore, the number of binding materials that have been improved by various types of structures is growing rapidly. Materials with the properties needed to meet the above challenges are close to the technology of nanomaterials, which are still used in the oil industry to a very small extent. The comparative analysis conducted by the author showed that using appropriate amounts of $\mathrm{SiO}_{2}$ nanoparticles it will be possible to design a cement paste with good rheological parameters, high strength and, at the same time, characterized by low filtration.
\end{abstract}

\section{Introduction}

One of the most important operations performed during drilling of oil or gas wells is the casing and cementing of the annular space. The success of this stage of works largely determines the durability and efficiency of production.

These works consist in inserting the casing pipes columns into the borehole and filling the new-created annular space (between the rock formation and the casing pipes) with a cement paste with a suitably selected composition and properties. After mixing the ingredients of the slurry, the hydration process begins. A transition state between a liquid state and a solid state is formed - the gel structure. At this time, the hydrostatic pressure is also reduced. The pressure imbalance between the hydrostatic pressure of the cement paste and the reservoir pressure contributes to the migration of gas or liquid in the annular space, which is a major problem in the perspective of the further exploitation of the well.

The next step is binding of the cement paste. Depending on the borehole conditions and the composition of the cement slurry, it can last from several hours to several days until the formation of a sealed cement coat.

The cement coat limits the migration of fluids (for example fresh water, brines, natural gas, crude oil) between the zones in rock formations and forms a permanent and tight connection in the annular space between the borehole wall and the casing column. In addition, it has a protective function to pipes - prevents corrosion and protects them against significant impact loads during further drilling. The cement stone seals the mud escape zones and other sections of the hole in which there are complications during drilling.

During selecting the cementing technology and designing the type of cement slurry, first of all there is a need to ensure the best tightness between the column of casing pipes and the level of reservoir rocks - the cement coat must ensure sealing at the cement-pipe-rock border, and be resistant enough to withstand the reservoir pressure in the hole, as well as the hydrostatic pressure created during drilling of the hole and other loads (for example thermal) $[1,2]$.

It is also important that the cement slurry must have adequate fluidity for a sufficiently long period to be able to be pumped through the column of casing pipes and pumped out into an annular space.

High requirements in relation to the properties of cement slurry and cement stone resulting from drilling ever deeper boreholes, determine the search for unconventional solutions and materials that will ensure the best possible results. Innovative solutions are needed to obtain a high-class end product. Recently, nanotechnology has become a synonym for development and progress - a dynamically developing branch of science dealing with both the creation and testing of materials whose at least one dimension ranges from 1 $\mathrm{nm}$ to $100 \mathrm{~nm}$ (see Fig. 1). These materials can be designed in such a way that they exhibit the desired physical, chemical or biological properties due to the size of their particles. This makes nanotechnology a promising area of research that allows the creation of materials with unusual properties. These molecules are typically used in small amounts, which is beneficial from

\footnotetext{
* Corresponding author: apiklow@agh.edu.pl
} 


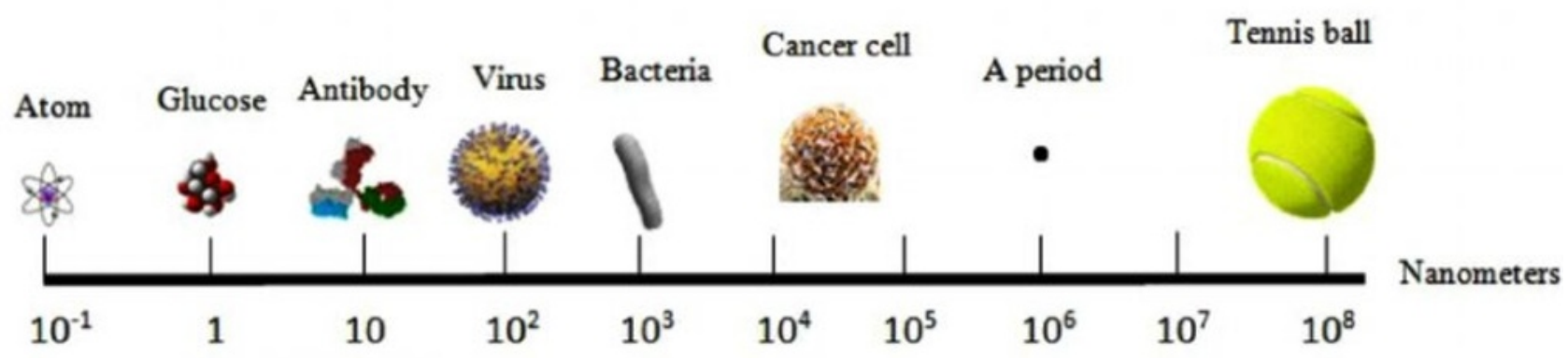

Fig. 1. Imaging of nanoscale [3].

an economic point of view. The use of appropriate amounts of these molecules will enable designing a cement grout with good rheological parameters, high strength and, at the same time, characterized by low filtration $[1,4]$.

\section{Nanosilica as an addition to cement slurries}

Nanomaterials and their unique properties have already found application in many industries, enabling the creation of materials with very beneficial properties, allowing to improve the features of existing products and create new ones. The improvement of mechanical parameters of materials containing the addition of nanoparticles is just one of many possibilities of their application.

Due to the growing requirements for cement grout used in the sealing operations of boreholes, as well as gas storage, resulting from drilling in deeper horizons, which involves high temperatures and pressures, there is a need for innovative measures that will significantly improve the technological parameters grout and cement stone. Such additives may be nanomaterials. The article presents the results of research on the impact of nanosilica on the rheological parameters of cement paste [4].

One of the most commonly used materials in nanotechnology is silica dioxide - $\mathrm{SiO}_{2}$ (see Fig. 2). Silica is a substance of high durability, not reacting with water and air. It is generally chemically passive and reacts only with boiling, concentrated aqueous solutions of $\mathrm{KOH}$ and $\mathrm{NaOH}$, melted with $\mathrm{Na}_{2} \mathrm{CO}_{3}$ and $\mathrm{K}_{2} \mathrm{CO}_{3}$ as well as with hydrogen fluoride or its aqueous solutions. $\mathrm{SiO}_{2}$ nanoparticles can be characterized by both random (amorphic structure) and ordered (crystalline structure) arrangement of atoms that build them. In addition, they may occur in another material, e.g. in metal alloys. Silica nanoparticles are obtained by decomposing the silica source compound. The properties of the final product are influenced by such process parameters as: temperature, duration of process or mixing speed. The classic method of producing silica with a spherical structure and a particle size of $0.5 \mathrm{~nm}$ to $200 \mathrm{~nm}$ is the Stöber method based on conducting a sol-gel process in an ammonia environment $[2,5]$.
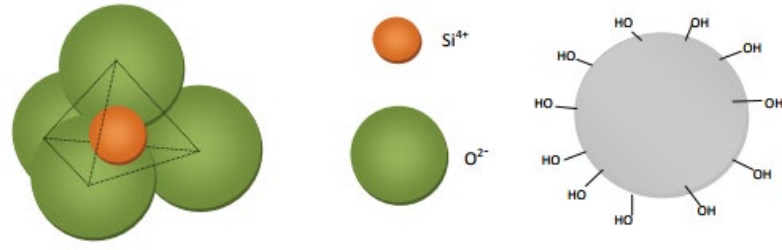

Fig. 2. Schematic diagram of the silica particle and silica nanosphere [2].

\section{$3 \mathrm{Nano} \mathrm{SiO}_{2}$ - the mechanism of action}

The mechanism of nanosilica's impact for enhancing the property of cement-based materials is typically attributed to two factors:

1. Nanosilica can act as a filler material to fill the interstitial space between cement particles, resulting in a higher packing density and lower porosity. Oilwell cement consists of primarily four main phases: $\mathrm{C}_{3} \mathrm{~S}, \mathrm{C}_{2} \mathrm{~S}, \mathrm{C}_{3} \mathrm{~A}$ and $\mathrm{C}_{4} \mathrm{AF}$. The $\mathrm{C}_{3} \mathrm{~S}$ and $\mathrm{C}_{2} \mathrm{~S}$ are mainly responsible for compressive strength development. When $\mathrm{C}_{3} \mathrm{~S}$ and $\mathrm{C}_{2} \mathrm{~S}$ react with water, they form $\mathrm{CSH}$ gel and $\mathrm{CH}$ (calcium hydroxide). The CSH gel acts as a binder for cement, consolidates the cement matrix, and provides strength to cement. Addition of silica would accelerate the formation of CSH gel, thereby helping cement gain the strength earlier. Moreover, because the fineness of silica particles, the particles are believed to fill the voids between the larger cement particles, resulting in a dense, solid matrix, even before any chemical reaction between the cement particles occurs [6].

2. Pozzolanic effect and crystallization control (preventing the formation of large crystals of $\left.\mathrm{Ca}(\mathrm{OH})_{2}\right)$. Pozzolanic effect depends on that the amorphous silica can slowly react with calcium hydroxide, one of the main hydration products of Portland cement, to form $\mathrm{CSH}$, which is the hydration product primairly responsible for the strength gain of cementitious materials. Several studies have been reported that concrete strength improvement as a result of the addition of small-size nanosilica is much higher than that of silica fume, even though the quantity used is much smaller for the former. This phenomenon has been explained by

\footnotetext{
$\overline{\text { * Corresponding author: apiklow@agh.edu.pl }}$
} 
a newly proposed strengthening mechanism of nanosilica in which it act as nucleation sites for $\mathrm{CSH}$, which not only accelerates early hydration of Portland cement, but also positively modifies the microstructure of $\mathrm{CSH}$ for stronger and more durable cement [2].

It was found that the rate of pozzolanic reaction depends on the specific surface area available in the reaction. One way to further improve the packing is to increase the grinding size by adding particles smaller than $300 \mathrm{~nm}$. Materials that need to be considered are: limestone and fine silica, namely silica dust and nanosilica. The addition of pozzolanic materials with very high granulation to the cement paste results in the formation of very fine hydration products, which in turn reduce the dimensions of the pores. Micro or nano pozzolanic particles are added as active substituents of Portland cement, and due to their reaction with calcium hydroxide to form a CSH phase, they improve the physical properties of cement paste $[7,8]$.

Analysis of research related to nanosilica indicates large discrepancies in their results. The reasons for these divergencies are most likely differences in the methods and conditions in which experiments were carried out, and above all the molar ratio of reactants, type of silica precursor, shape (nanospheres, fibers) and type of nanoparticles, reaction time in the sol-gel method, as well as the degree of dispersion of particles in a cement matrix (the diameter of $\mathrm{SiO}_{2}$ particle is usually in the range from 5 to $1000 \mathrm{~nm}$, and their specific surface area in the range from about 3 to $\left.550 \mathrm{~m}^{2} / \mathrm{g}\right)[9,10]$.

\section{Materials and methods}

Rheology and fluid loss control (FLC) are two areas basic to drilling fluids that appear to be suited for the application of nanotechnology [11].

Cement rheology is a basic controlling factor which ensure cement performance as well as assists in measuring the pumpability of cement slurry. In rheological studies, parameters like apparent flow, plastic viscosity, yield point etc., of a cement slurry are measured using a rotational viscosimeter.

The rheological properties of the different formulas were measured using a rotational standard Fann type viscosimeter. Viscometric data were obtained at fixed speeds of $600,300,200,100,60,30,20,10,6,3,2,1$ $\mathrm{rpm}$, which give Newtonian shear rates on the inner fixed cylinder of $1022.04 ; 511.02 ; 340.7 ; 170.4 ; 102.2$; $51.1 ; 34.08 ; 17.04 ; 10.22 ; 5.11 ; 3.41$ and $1.70 \mathrm{~s}^{-1}$, respectively [12]. The readings were taken from high to low speeds firstly, then in opposite site. Afterwards, the average was calculated. The rheological parameter estimation was done according Herschel-Bulkley model, given by equation 1 [13]:

$$
\tau=\tau_{y H B}+k_{H B} \gamma^{n_{H B}}
$$

which uses three rheological parameters, the HerschelBulkley yield stress $\left(\tau_{y H B}\right)$, the flow consistency index
$\left(k_{H B}\right)$ and the flow behaviour index $(n)$ that shows shear thinning or shear thickening behaviour [13].

The study of fresh cement slurry includes rheological parameters: plastic viscosity, apparent viscosity, yield point, structural strength, spreading, contractual viscosity, settlement (free water emission) and filtration. Measurements were made according to the standard provisions (Baroid weight for determination of density, beveled cone for marking spreading, Ford's mug no. 4 for marking contractual viscosity and measuring cylinder for free water emission).

G type cement by Dyckerhoff was chosen due to the wider range of applications. On the basis of previous studies and conditions of boreholes in Poland, slurry containing additives in the form of defoamer $(0.5 \%)$, plasticizer $(0.3 \%)$, retarder $(0.05 \%)$ and filtration regulator $(0.4 \%)$, each by weight of cement (bwoc) [6].

Five concentrations of AkzoNobel nanosilica (Cembinder 8) were used, by weight of cement too, the last sample was a basis. The proposed water-cement coefficient $(w / c)$ of the tested sealing slurries will be constant and have been planned at the level of 0.55 .

Cement should be weighed using an electronic weight (with an uncertainty of indications $+/-0.1 \%$ of the weighed substance). The mixture is prepared using a one-liter mixer, with bottom drive, equipped with paddle agitators. The temperature of the mixing water and cement should be $23^{\circ} \mathrm{C}+/-1^{\circ} \mathrm{C}$.

Cement for the preparation of mixture, according to the requirements of ISO 25911-1 and ISO 3310-1, is sifted through three wire screens with the square mesh dimensions $1.0 \mathrm{~mm}, 0.20 \mathrm{~mm}$ and $0.08 \mathrm{~mm}$.

For the preparation of slurry cement is sieved by three successive sieves (standard cement crumbling residual on a sieve $0.20 \mathrm{~mm}$ not more than $2 \%$, no 0.08 $\mathrm{mm}$ more than 20\%). Measured volume of water and liquid additives resulting from the assumed $\mathrm{w} / \mathrm{c}$ coefficient are poured into the container of the mixer and then within 15 seconds adding the previously weighed mass of cement and dry additives with continuous mixing while maintaining the rotational speed of the stirrer at $4,000 \mathrm{rpm}+/-200 \mathrm{rpm}$. Then, the stirring is continued with the speed of $12,000 \mathrm{rpm}+/-500 \mathrm{rpm}$ for $35 \mathrm{~s}+/-1 \mathrm{~s}$. The prepared mixture is tested in the set order, in the shortest possible time.

\section{Results and discussions}

Using the rheological data obtained from the Fann viscometer and using Rheosolution 3.0, the most appropriate rheological model was estimated. In each case Hershel-Bulkley model was the best fit, for which a full correlation was obtained (Pearson coefficient almost equal 1). The coefficients necessary for the later estimation of flow resistances are given below. Table 1 presents a results of a rheology parameters research. Table 2 and Figure 3 shows a rheological model fitting, whereas Figure 4 and Figure 5 presents a comparative charts of rheological parameters. Formulas (2) - (4) define rheological parameters: plastic viscosity, apparent 
viscosity and yield point based on appropriate viscometer readings [13]:

$$
\eta_{p}=M_{600}-M_{300}
$$

$$
\begin{gathered}
\eta_{a}=\frac{M_{600}}{2} \\
\tau_{y}=M_{300}-\eta_{p}\left[\frac{l b}{100 f t^{2}}\right]=\tau_{y} \cdot 0,4788\left[\frac{\mathrm{N}}{\mathrm{m}^{2}}\right]
\end{gathered}
$$

Table 1. Results of experiments

\begin{tabular}{|c|c|c|c|c|c|c|c|}
\hline Parameter & Symbol & $0 \% \mathrm{n}-\mathrm{SiO}_{2}$ & $0,5 \% \mathrm{n}-\mathrm{SiO}_{2}$ & $1 \% \mathrm{n}-\mathrm{SiO}_{2}$ & $1,5 \% \mathrm{n}-\mathrm{SiO}_{2}$ & $2 \% \mathrm{n}-\mathrm{SiO}_{2}$ & $2,5 \% \mathrm{n}-\mathrm{SiO}_{2}$ \\
\hline $\begin{array}{c}\text { Pearson`s } \\
\text { correlation } \\
\text { coefficient [-] }\end{array}$ & $\checkmark$ & 1,0000 & 0,9998 & 0,9999 & 0,9995 & 0,9995 & 0,9996 \\
\hline yield point [Pa] & $\tau_{y H B}$ & 1,2721 & 2,0439 & 1,8539 & 4,4664 & 6,5070 & 7,6688 \\
\hline $\begin{array}{l}\text { flow consistency } \\
\text { index } P a * s^{n}\end{array}$ & $k_{H B}$ & 0,3966 & 0,4273 & 0,4583 & 0,4089 & 0,5182 & 0,8029 \\
\hline $\begin{array}{c}\text { flow behaviour } \\
\text { index }[-]\end{array}$ & $n_{H B}$ & 0,8365 & 0,8213 & 0,8055 & 0,8366 & 0,8106 & 0,7600 \\
\hline
\end{tabular}

\begin{tabular}{|c|c|c|c|c|c|c|}
\hline $\mathrm{w} / \mathrm{c}=0,55$ & $0 \% \mathrm{n}-\mathrm{SiO}_{2}$ & $0,5 \% \mathrm{n}-\mathrm{SiO}_{2}$ & $1 \% \mathrm{n}-\mathrm{SiO}_{2}$ & $1,5 \% \mathrm{n}-\mathrm{SiO}_{2}$ & $2 \% \mathrm{n}-\mathrm{SiO}_{2}$ & $2,5 \% \mathrm{n}-\mathrm{SiO}_{2}$ \\
\hline plastic viscosity [mPa*s] & 111 & 106 & 99 & 114 & 119.5 & 127.5 \\
\hline apparent viscosity [mPa*s] & 128.75 & 125.5 & 120.5 & 136.25 & 146 & 160 \\
\hline yield point [Pa] & 16.9974 & 18.6732 & 20.5884 & 21.3066 & 25.3764 & 31.122 \\
\hline $\begin{array}{c}\text { structural strength [mPa*s, } \\
\text { after 10s/after 10 min] }\end{array}$ & $8 / 9$ & $10 / 17$ & $11 / 22$ & $12 / 25$ & $13 / 30$ & $15 / 38$ \\
\hline density [kg/m 3 ] & 1,80 & 1,80 & 1,81 & 1,82 & 1,82 & 1,83 \\
\hline spreading [mm] & $>260$ & $>260$ & 260 & 245 & 225 & 210 \\
\hline contractual viscosity [s] & 27 & 29 & 30 & 39 & 52 & 60 \\
\hline settlement [\% after 2h] & 2 & 1,5 & 1 & 0,5 & 0 & 0 \\
\hline filtration [ml after 30 min] & 20 & 17 & 10 & 12 & 13 & 15 \\
\hline
\end{tabular}

Table 2. The coefficients of estimation.
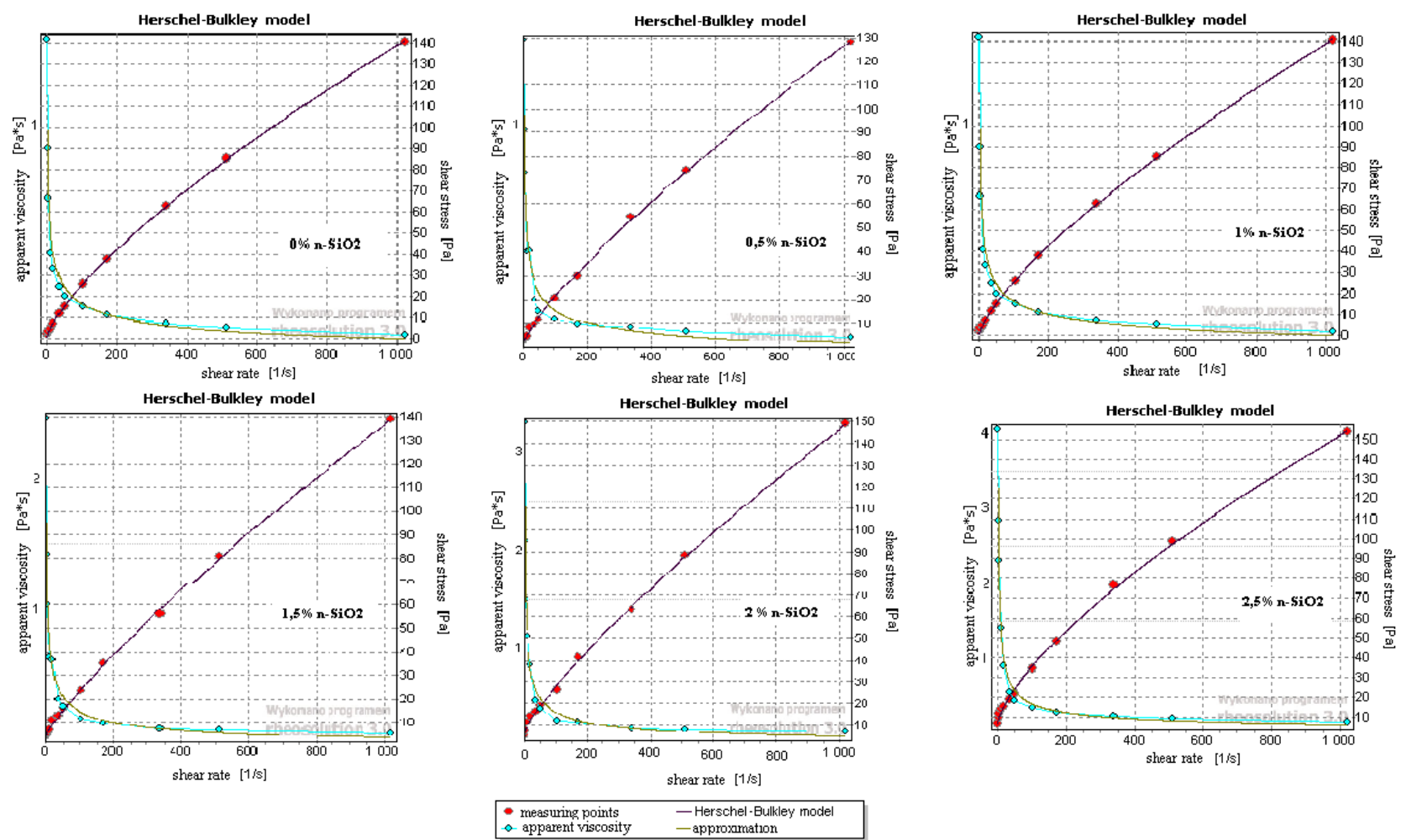

$\begin{array}{ll}\text { - measuring points } & \text { - Herschel-Eulk } \\ \text { a apparent viscosity } & \text {-approxmation }\end{array}$

Fig. 3. Diagrams from Rheosolution 3.0 - rheological model fitting. 


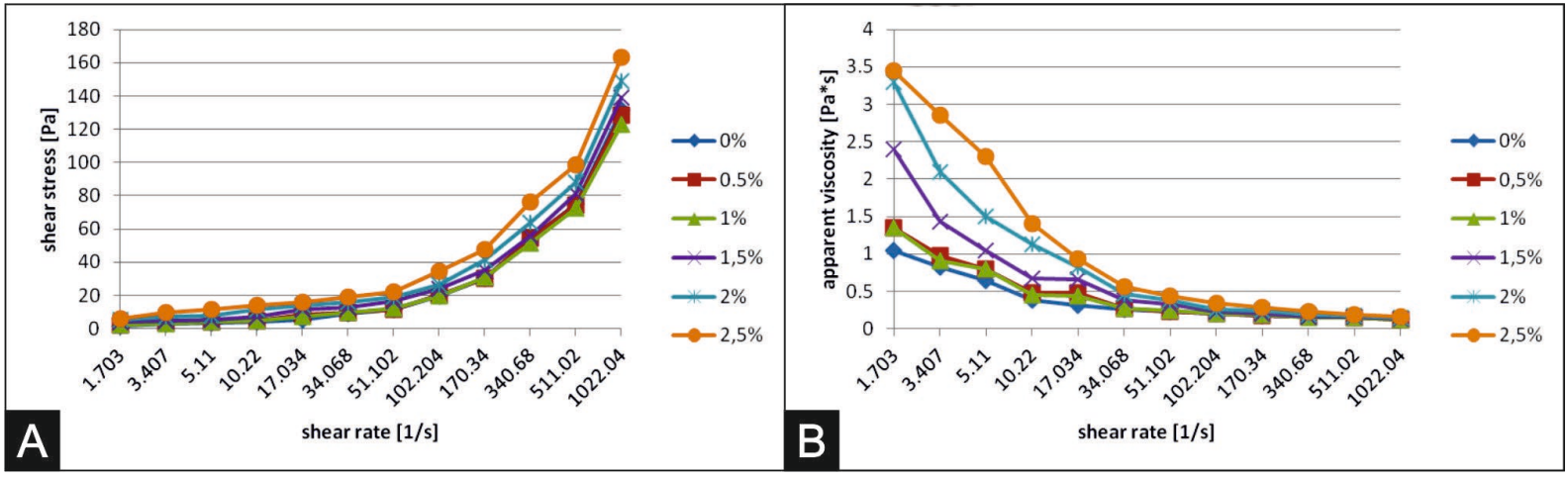

Fig. 4. Summary diagrams: A) shear rate vs. shear stress, B) shear rate vs. apparent viscosity.

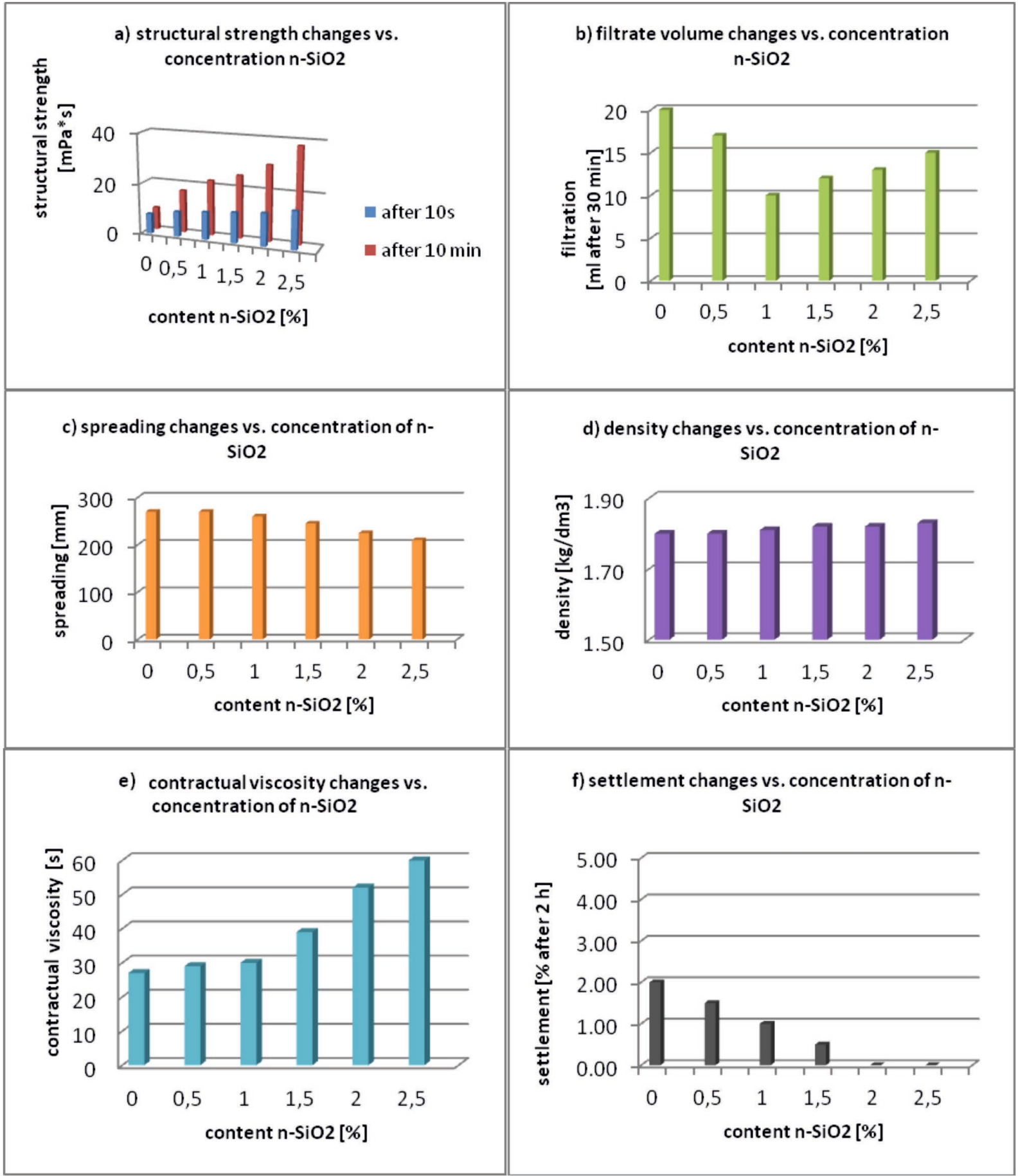

Fig. 5. Diagrams illustrating of changes in particular parameters as a function of concentration of nanosilica. 


\section{Conclusions}

Based on the results of the research, the following conclusions can be made:

- the addition of nanosilica to the cement slurry results in a slight deterioration of its miscibility and viscosity parameters (yield point, spreading),

- growth of density for all samples with the addition of nanosilica is almost unnoticed,

- spreading and contractual viscosity are slightly worsened but the slurry has preserved its liquidity,

- $\quad$ smaller spreading, filtration, settlement and bigger viscosity - change of these parameters shows that after the addition of nanosilica, water-binding reactions take place, which reduces fluidity and increases consistency (bigger $\mathrm{k}_{\mathrm{HB}}$ coefficient),

- obtaining the optimal parameters (high structural strength with the smallest filtration and relatively low amount of settling, consistency and yield point) indicates a concentration of $1 \%$ (bwoc) as the bestchosen concentration to using in drilling wells (for this type of nanosilica),

- these molecules are usually used in small quantities, which is economically advantaeous,

- due to the possibility of regulating rheological parameters, the cement slurry with nanosilica and other additives with the required properties can be easily designed.

Laboratory tests of technological parameters of fresh cement slurries with added nanosilica have show that in an optimal dose (Fig. 4), with a relatively low increase in rheological parameters (increased yield point - greater increase in flow resistance, but the plastic viscosity even decreased), structural strength increases (better displacement of mud cake) and free water emission was reducted (settlement, filtration). The addition of colloidal nanosilica practically does not affect the density change.

Addiction of nanosilica increases the possibility of application of cement slurry used to seal the casing - the particle size of nanosilica greatly influences the structural properties of the material, increasing the range of its application. This unique property allows treatment of the formation to a desired depth of the wellbore. Moreover, the entire system is environmentally acceptable $[14,15]$.

Nanomaterials, such as nanosilica, at the optimal concentration, can be used for plugging and sealing water- or gas-producting zones (bottom-water coning, gas coning, natural fractures, etc.), or a water shutoff. Development of using the nanosilica-containing slurry recipes for cementing casing pipes is fully justified and can be still conducted (for instance by testing cement stones, which is the next stage of author`s work).

\section{Summary}

The need to introduce innovative solutions and products of higher quality has allowed nanotechnology to emerge in a large group of industries, including drilling. The extraordinary properties of nanoparticles and nanocomposites have made them synonymous with modernity and development. The examined nanoparticles have the ability to maintain optimal rheological properties so that many drilling problems can be efficiently mitigated. Their low concentration in the drilling system, compared to other conventional drilling additives, provides a basis for more efficient drilling practices $[7,14]$

The cement slurries with silica nanoparticles presented in this article may be the basis for the development of a wide range of innovative recipes for sealing slurries.

\section{References}

1. E. Dębińska, Geopetrol Scientific and Technical Conference, Poland (2016)

2. E. Dębińska, Nafta-Gaz, LXXI, 5, 290-300 (2015)

3. V. Kułynycz, A. Pikłowska, O. Kulynych, AGH Drilling Oil Gas 35 (2017, to be published)

4. E. Dębińska, Nafta-Gaz, LXXII, 4, 251-261 (2016)

5. R. Jeziórska, B. Świerz-Motysia, M. Zielecka, M. Studziński, Polimery, 54, 10, 727-736 (2009)

6. A. Pikłowska, Proceedings of International multidisciplinary scientific geoconference SGEM 2017, Vienna, Austria, vol. 17, 357-364 (2017)

7. R.C. Patil, A. Deshpande, SPE International Oilfield Nanotechnology Conference, Noordwijk, The Netherlands, 12-14 June 2012, SPE 155607 (2012)

8. A.K. Santra, P. Boul, X. Pang, SPE International Oilfield Nanotechnology Conference, Noordwijk, The Netherlands, 12-14 June 2012, SPE 156937 (2012)

9. E. Horszczaruk, E. Mijowska, K. Cendrowski, S. Mijowska, P. Sikora, Cement Wapno Beton, 18/80, 1, 24-32 (2013)

10. H. Shoukry, S.S. Shebl, I.S. Khalil, Cement Wapno Beton, 18/80, 1, 17-22 (2014)

11. K.P. Hoelscher, S. Young, J. Friedheim, S. de Guido, $11^{\text {th }}$ Offshore Mediterranean Conference and Exhibition in Ravenna, Italy, 20-22 March 2013 (2013)

12. Specifications for Materials and Testing for Well Cements. API Specification 10 (SPEC 10) Fifth Edition, July 1, 1990

13. R. Wiśniowski and K. Skrzypaszek, Wiertnictwo, Nafta, Gaz, 23, 523-532 (2006)

14. P.R. Patil, R. Kalgaonkar, SPE International Oilfield Nanotechnology Conference, Noordwijk, The Netherlands, 12-14 June 2012, SPE 154917 (2012)

15. K. Sobolev, I. Flores, R. Hermosillo, L.M. TorresMartinez, Proceedings of ACI Session on „Nanotechnology of Concrete: Recent Developments and Future Perspectives" November 7, 2006, Denver, USA, 91-118 (2006)

\footnotetext{
*Corresponding author: apiklow@agh.edu.pl
} 